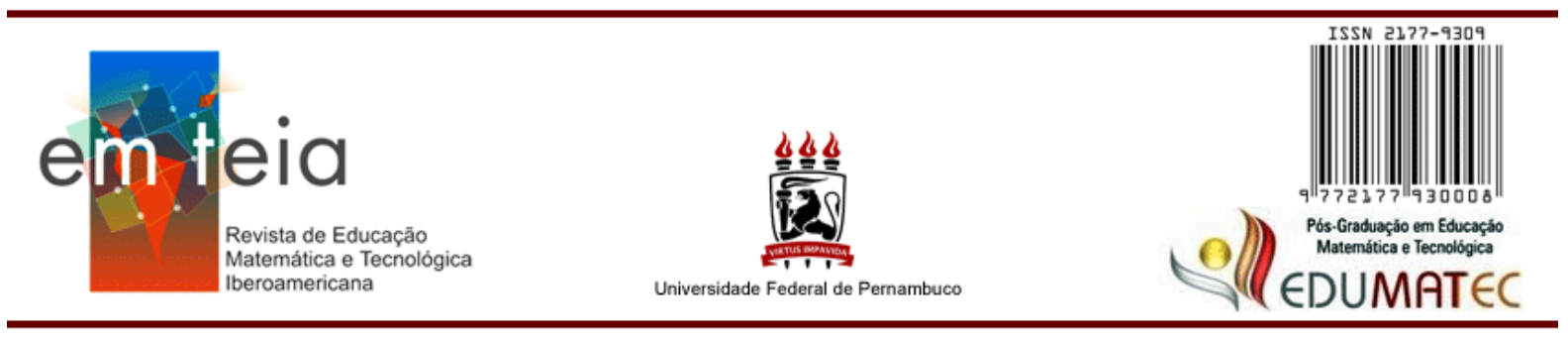

\title{
O CUIDADO DE SI COMO DISPARADOR PARA DOCÊNCIAS OUTRAS EM MATEMÁTICA
}

\author{
Taking care of yourself as a trigger for other teaching in mathematics
}

\author{
Veronica de Lima Mittmann \\ Mestrado em Educação em Ciências pela UFRGS \\ Universidade Federal do Rio Grande do Sul - RS - Brasil \\ veronicalimam@hotmail.com
}

\begin{abstract}
Resumo
Este artigo intenciona problematizar a Docência em Matemática por entender que esta tem nos constituído como sujeitos de determinados discursos que têm produzido determinados modos de ser, perceber e estar no mundo. Desta forma, a fim de colocar a matemática em suspensão, utilizamos como ferramenta teórica os conceitos de disciplina, norma e cuidado de si do teórico Michel Foucault. Neste sentido, ao longo deste texto pudemos perceber que a Matemática tem fortalecido e sido fortalecida pelo poder disciplinar e pela norma, e deste modo, pode ter colaborado para a produção, do que Foucault denomina o Sujeito Moderno. Com isto, buscamos nos estudos de Michel Foucault sobre o cuidado de si greco-romano, a possibilidade de potencializarmos o nosso pensamento, a fim de tentar compreender como poderiam ser realizadas fissuras na Matemática que produz e é produzida no campo educacional, a fim de possibilitar a emergência de matemáticas outras.
\end{abstract}

Palavras-Chave: Docência. Matemática. Estudos foucaultianos. Disciplina. Cuidado de si.

\begin{abstract}
This article intends to problematize Teaching in Mathematics by understanding that it has constituted us as subjects of certain discourses that have produced certain ways of being, perceiving and being in the world. In this way, in order to put the mathematics in suspension, we use as theoretical tool the concepts of discipline, norm and self-care from Michel Foucault's theory. In this sense, throughout this text we can perceive that mathematics has strengthened and been strengthened by the disciplinary power and the norm, and in this way, may have collaborated for the production, of what Foucault calls as Modern Subject. We search in the studies of Michel Foucault Greco-Roman self-cake, the possibility of potentializing our thinking, in order to try to understand how could be realized cracks in mathematics that produces and is produced in the educational field, in order to enable the emergence of other mathematics.
\end{abstract}

Keywords: Teaching, mathematics, Foucauldian studies, discipline, self care.

\section{Primeiras palavras}

É sua própria alma que é preciso criar no que se escreve; porém, assim como o homem traz em seu rosto a semelhança natural com seus ancestrais, 
também é bom que se possa perceber no que ele escreve a filiação dos pensamentos que se gravaram em sua mente (FOUCAULT, 2014a, p. 149).

Convidamos Foucault para iniciarmos o nosso artigo, pois como o autor sugere na epigrafe acima, "é sua própria alma que é preciso criar no que se escreve". Com isto, neste texto, criamos e fomos criados por esta escrita. Neste sentido, os vocábulos que aqui se compõem foram sendo traçados pelas experiências que fomos tendo no mundo e ao ler textos que nos tocaram e que, de certa maneira, foram nos guiando neste percurso de leituras e escritas.

Por acreditarmos que nos transformamos pelos textos que criamos, esta escrita é uma possibilidade de sermos diferentes, ou seja, de abrir janelas outras em nossas almas, para enxergar outros horizontes e outros céus, pois "há momentos na vida em que a questão de saber se é possível pensar de forma diferente da que se pensa e perceber de forma diferente da que se vê é indispensável para continuar a ver ou a refletir" (FOUCAULT, 2014a, p. 191). No entanto, deixar nascer outras formas de si é um exercício doloroso, pois faz perceber que muitas das verdades nas quais nos firmamos são construídas, ou seja, não são verdades absolutas ou a priori e, por vezes, experimentamos a sensação de estarmos soltos no mundo, ou seja, não há nada em que possamos nos agarrar que não seja provisório.

Se as verdades são invenções, podemos construir outras, que propiciem maneiras menos opressoras de estar no mundo. Todavia, mesmo as verdades em que acreditamos e que nos são caras, também são transitórias, ou seja, verdades de um tempo. Além disso, também compreendemos que nossos estudos não são neutros, ou seja, não estão fora deste jogo de verdades, pois “[...] todos os discursos, incluindo aqueles que são objeto de nossa análise e o próprio discurso que construímos como resultado de nossas investigações, são parte de uma luta para construir as próprias versões de verdade" (PARAÍSO, 2014, p. 29).

O desafio deste artigo é o de pensar como a ética do cuidado de si greco-romana poderia possibilitar pequenas rupturas nas formas de compreender a Docência em Matemática, já tão sedimentadas no campo educacional. Desta maneira, compartilhamos com Foucault, que

[...] o motivo que me impulsionou é muito simples. Para alguns, espero que ele possa bastar por si só. É a curiosidade: o único tipo de curiosidade que, de qualquer forma, vale a pena ser praticada com um pouco de obstinação: não aquela que busca se assimilar ao que convém conhecer, mas a que permite desprender-se de si mesmo (FOUCAULT, 2014a, p. 191). 
Assim, para estranharmos nosso pensamento, escrevemos estas páginas, que pretendem dar outros contornos, ou talvez, inventar formas outras para a compreensão da Docência em Matemática que é produzida na sala de aula e que nos produz como sujeitos de determinados modos. Nossa intenção é a de perceber possíveis espaços de liberdade para ser e fazer diferente. Neste sentido, a fim de pensar docência outras em matemática, utilizamos como ferramentas teóricas os conceitos de disciplina, norma e cuidado de si de Michel Foucault.

\section{A produção de sujeitos disciplinares na escola moderna}

O indivíduo é sem dúvida o átomo fictício de uma representação "ideológica" da sociedade; mas é também uma realidade fabricada por esta tecnologia especifica de poder que se chama "disciplina". Temos que deixar de descrever sempre os efeitos de poder em termos negativos: ele "exclui", "reprime", "recalca", "censura", "abstrai", "mascara", "esconde". Na verdade, o poder produz; ele produz realidade; produz campos de objetos e rituais da verdade (FOUCAULT, 1999, p. 161).

Foucault, no excerto acima, afirma que tanto o sujeito quanto a realidade e a verdade são fabricadas. Desta forma, se somos construídos, não existiria uma essência humana, isto é, um "Eu" interior que iria se revelando à medida que fossemos crescendo e que atingiria seu potencial na vida adulta. Neste sentido, se não somos, mas estamos nos tornando, pois não haveria nada a ser desvelado ou descoberto em nossa subjetividade, estaríamos em constante construção e desconstrução de si. No entanto, esta maneira de compreender o sujeito se contraporia a algumas correntes filosóficas que

[...] tenta[m] articular num discurso a natureza originária, pré-estabelecida, essencial de uma estrutura subjetiva (a alma da reminiscência platônica, a res cogitans de Descartes, o Eu como pura função transcendental em Kant, a consciência doadora de sentido em Husserl (GROS, 2006, p. 128).

Neste sentido, nos tornamos humanos nas relações que estabelecemos com os outros humanos, com os animais, com as coisas, ou seja, nossas experiências no mundo propiciam que sejamos subjetivados de determinada maneira, que seria singular, isto é, haveria pequenas variações de humano para humano. Deste modo, quando nascemos herdamos um mundo já constituído pela linguagem e aprendemos desde cedo a nomear as coisas e os afetos. Não que não haja a materialidade do mundo, ou nas sensações, mas "somente após a experiência vivida ter sido transposta para uma linguagem é que se tem uma experiência objetiva" 
(BRAIDA, 1994, p. 35). Assim, o mundo que conhecemos é uma invenção, pois "as formas fundamentais do intelecto são formas fictícias que agora funcionam como constitutivas, que agora valem como o a priori” (BRAIDA, 1994, p. 37). Portanto, significar a realidade somente nos é possível porque aprendemos as suas regras. Ao entender a realidade como ficção, compreendemos que seria improvável acessar uma realidade real, neutra ou fundamental.

Na sociedade atual, o animal humano, desde que nasce, precisa ser "disciplinado" para que possa se tornar o que Foucault denomina Sujeito Moderno. Assim, a primeira instituição disciplinadora seria, de forma preponderante, a família. Neste lócus, a criança é ensinada a andar e deve fazê-lo de determinada forma e em determinados lugares, a ouvir e a falar, e ainda, o que, quando, como e com quem falar; aprende o que, quando e como comer, ou seja, em nosso corpo vão se inscrevendo "modos de ser humano", pois

O corpo é uma singularidade somática. Ele possui um quantum único de energia passiva a ser trabalhada. Mas em si mesmo, o corpo não é nada: é um dado bruto, uma energia virtual, passiva de ser ativada conforme um canal de força que age administrando-a, canalizando-a, vertendo-a para essa ou aquela atividade (CARVALHO, 2015, p. 189).

No entanto, se a primeira instituição de disciplinamento é a família, poderíamos supor que em seguida ou concomitantemente viriam as escolas, que dão continuidade aos processos de disciplinarização, que têm como função a docilização do corpo, ou seja, "é dócil um corpo que pode ser submetido, que pode ser utilizado, que pode ser transformado e aperfeiçoado (FOUCAULT, 1999, p. 118). Com isto, segundo Foucault (1999), a disciplinarização produziria individualidades dotadas de quatro características como a de ser celular, ou seja, cada aluno pertence a uma escola. Neste local, os alunos têm seu espaço demarcado, ou seja, “cada indivíduo no seu lugar; e em cada lugar, um indivíduo" (FOUCAULT, 1999, p. 123). Além disso, os alunos pertencem a uma turma, isto é, "o espaço disciplinar tende a se dividir em tantas parcelas quanto corpos ou elementos há a repartir" (FOUCAULT, 1999, p. 123). Esta divisão não se dá de qualquer maneira, mas de forma organizada e controlada, ou seja, a disposição dos alunos em filas e em classes possibilita uma maior visibilidade dos mesmos pelos professores. Também há uma hierarquia neste espaço celular, ou seja, o professor vigia e avalia os alunos, mas é vigiado e avaliado por um supervisor que é vigiado e avaliado por um diretor e assim, sucessivamente. Além disso, os lugares que cada um ocupa parecem lhes conferir valor, ou seja, um Secretário de Educação parece ser mais valorizado do que um professor, mas seria menos prestigiado do que um Ministro da Educação. Outra característica 
da individualidade disciplinada seria a de ser orgânica, ou seja, os corpos são treinados, a fim de que haja uma maior eficiência dos gestos. Assim, as atividades podem ser realizadas com maior qualidade no menor tempo possível. Com isto, haveria um uso exaustivo do tempo, a fim de evitar qualquer tipo de ociosidade. Neste sentido,

O ato é decomposto em seus elementos; é definida a posição do corpo, dos membros, das articulações; para cada movimento é determinada uma direção, uma amplitude, uma duração; é prescrita sua ordem de sucessão. O tempo penetra o corpo, e com ele todos os controles minuciosos do poder (FOUCAULT, 1999, p. 129).

Outra característica da individualidade disciplinar seria a de ser genética pela acumulação do tempo, ou seja, "adicionar e capitalizar o tempo representa a possibilidade de articular proveitosamente as elaborações temporais de cada ato e dos atos correlacionados" (FONSECA, 2016, p. 78). Desta forma, na escola, os alunos têm seu tempo organizado, sendo a aprendizagem dividida em anos letivos, nos quais em geral, os alunos estudam quatro horas por dia, com exceção dos finais de semana e dos períodos de férias. Além desta organização do tempo, digamos assim, de estudos, os alunos também tem seu tempo de vida dividido, pois quando ingressam na escola, integram o primeiro ano, no qual os exercícios intelectuais e físicos correspondem a sua idade. Assim, os exercícios começariam em um grau de dificuldade mais simples e iriam ficando cada vez mais complexos, com o avanço dos anos escolares e o aumento da idade. Para evoluir de um estágio a outro seria preciso uma prática sistemática de exercícios que "tende para uma sujeição que nunca termina de se completar" (FOUCAULT, 1999, p. 137). Outra característica da individualidade disciplinar seria a combinatória, ou seja, "a disciplina não é mais simplesmente uma arte de repartir os corpos, de extrair e acumular o tempo deles, mas de compor forças para obter um aparelho eficiente" (FOUCAULT, 1999, p. 138). Cada indivíduo seria responsável pelo desempenho de algumas atividades que se combinariam entre si, e que, para serem desenvolvidas da melhor forma possível, teriam um centro de comando, ou seja, um local responsável pela distribuição e pelo controle da execução de todas as atividades de um grupo de indivíduos e que, a fim de que sejam realizadas da melhor forma possível, se utiliza de táticas e de estratégias.

Quando me refiro à estratégia, entendo-a na ordem do planejamento, da trajetória a ser tomada; e "por táticas entendo as ações/práticas micropolíticas que conduzem as condutas dos sujeitos, encaminhando para formas específicas de governamento das subjetividades" (PINHEIRO, 2014, p. 33). 
Desta maneira, a disciplina, a fim de produzir os sujeitos disciplinares se utiliza de alguns instrumentos para adestrar como: a vigilância hierárquica, que possibilita olhar sem ser visto, e assim viabilizar "[...] um controle interior, articulado e detalhado - para tornar visíveis os que nela se encontram; mais geralmente, a de uma arquitetura que seria um operador para a transformação dos indivíduos [...]” (FOUCAULT, 1999, p. 144) que funciona como um microscópio do comportamento, controlando os mínimos gestos. Já a sanção normalizadora seria as micropenalidades que pretendem reprimir todo comportamento considerado inadequado (atraso, desatenção, insolência, indecência), ou seja, que confrontam a norma. Estas punições poderiam ser: castigos físicos, privações ou humilhações. Neste sentido "a disciplina recompensa unicamente pelo jogo das promoções que permitem hierarquias e lugares; pune rebaixando e degradando. O próprio sistema de classificação vale como recompensa ou punição" (FOUCAULT, 1999, p. 151). Também é aplicado o exame que combina as técnicas da vigilância e da sanção normalizadora que "permite ao mestre, ao mesmo tempo em que transmite seu saber, levantar um campo de conhecimentos sobre seus alunos" (FOUCAULT, 1999, p. 155) e a partir deste conhecimento, classificá-los. Neste sentido, o exame possibilita tornar visível os conhecimentos adquiridos pelos alunos e ainda, punir aqueles que não sabem, pela nota.

Além da disciplina-corpo que já foi comentada ao longo destes escritos, também gostaríamos de tratar brevemente, da disciplina-saber. Desta forma, para ser considerado um bom aluno, seria necessário cumprir da melhor forma possível o que a escola propõe, tanto na disciplina-corpo quanto na disciplina-saber, e ainda, se sair melhor do que a maioria, haja vista que:

Ao falar em disciplina-saber, refiro me às próprias unidades, a cada um dos compartimentos nos quais se dividem os saberes ou às maneiras como se fracionam e se articulam os saberes. Assim, em torno do eixo corporal estão as relações de subordinação, a submissão física às regras, a ordem no funcionamento (mesmo institucional pois, nesse caso, o ordenamento da instituição é, pelo menos em parte, o resultado dos ordenamentos dos corpos), etc. e em torno de um eixo cognitivo estão as disposições dos saberes, suas relações, suas manifestações apreensíveis, etc. (VEIGA-NETO, 1996, p. 58).

Assim, a disciplina-corpo atuaria em conjunto com a disciplina-saber nas instituições escolares, a fim de conformar um "corpo-dócil". Haja vista que um corpo disciplinado estaria mais propicio a aprender um saber que se estruturaria também em disciplinas e de maneira concomitante, uma mente que se adaptou a uma disciplina-saber teria mais facilidade de ter 
seu corpo disciplinado pelas normas escolares. Com isto, ambos os eixos disciplinares: disciplina-corpo e disciplina-saber "se complementam, se reforçam mutuamente, para produzir o que se pode chamar de sujeitos disciplinares" (VEIGA-NETO, 1996, p. 58).

Segundo Foucault (2008), para que se possa disciplinar os sujeitos, são utilizadas as técnicas de normatização e de normalização. As técnicas de normação são as utilizadas na sociedade disciplinar, a fim de aproximar os sujeitos da norma, ou seja, a vigilância, as sanções normalizadoras, o exame, a organização dos tempos e dos espaços, etc. Assim, enquanto a normatização se dirige ao indivíduo, a normalização, por serem as técnicas utilizadas no biopoder, que emerge no século XVIII, se aplicam à população, ou seja, "um conjunto de indivíduos que são pensados coletivamente como uma unidade descritível, mensurável, conhecível e, por isso mesmo, governável" (VEIGA-NETO, 2007, p. 955). As técnicas de normalização se trata do estabelecimento de uma curva de normalidade que parte de "certas distribuições consideradas, digamos assim, mais normais que as outras, mais favoráveis em todo caso que as outras. São essas distribuições que vão servir de norma" (FOUCAULT, 2008, p. 83). Com isto, a norma se aplica a todos os indivíduos, ou seja, "ambos, o normal e o anormal, estão na norma; ambos são casos da norma, ainda que estejam situados em polos opostos" (VEIGA-NETO, 2009, p. 99).

Percebemos que a Matemática também é instrumento de subjetivação, pois constrói modos de ser aluno/aluna, de compreender o conhecimento e o que se entende por razão e ciência. A matemática foi por um longo tempo compreendida como conhecimento racional e por isto, seria mais facilmente aprendida pelos meninos do que pelas meninas que teriam o raciocínio lógico menos desenvolvido (WALKERDINE, 1995). Também se acreditava que para aprender Matemática seria necessário ser um sujeito disciplinado, ou seja, ser atento, organizado, racional, empenhado, etc. Com isto,

[...] não fosse a maneira como ela é ensinada, a maneira como o consenso da matemática se organiza, funcionando em circuito fechado, tem seus valores, determina o que é bem (verdade) ou mal (falso) na matemática etc. isso não significa de forma alguma que a matemática seja apenas um jogo de poder, mas que o jogo de verdade da matemática esteja de certa maneira ligado, e sem que isso abale de forma alguma a sua validade, a jogos e a instituições de poder. É claro que, em um certo número de casos, as ligações são tais que é perfeitamente possível fazer a história da matemática sem levar isso em conta, embora essa problemática seja sempre interessante e os historiadores da matemática tenham começado a estudar a história de suas instituições (FOUCAULT, 2014a, 275). 
Assim, poderíamos inferir que a matemática tem se beneficiado do poder disciplinar e em contrapartida, também fortalecido este poder, pois tem sido utilizada como um instrumento de normalização e de normação. Desta forma, compreendemos que aquilo que ensinamos constrói sujeitos de determinados modos que construirão diferentes configurações de sociedade. Somos responsáveis por aquilo que ensinamos, ou seja, temos mais competência do que os nossos alunos, em determinados assuntos, porque estudamos e nos especializamos e deste modo, não vemos “onde está o mal na prática de alguém que, em um dado jogo de verdade, sabendo mais do que um outro, lhe diz o que é preciso fazer, ensinando-lhe, transmite-lhe um saber, comunica-lhe técnicas; (FOUCAULT, 2014a, 278). No entanto, acreditamos que a educação, se não alcança mudar o mundo, pode, ao menos provocar pequenas fissuras nas verdades e na realidade que conhecemos, a fim de que esta possa ser vivida com mais intensidade, com mais alegria e entusiasmo. Neste sentido, acreditamos que o cuidado de si greco-romano pode nos ajudar a pensar em docências outras que fissurem a Matemática escolar.

\section{A CULTURA GRECO-ROMANA DO CUIDADO DE SI E A ESCOLA MODERNA}

Nenhuma técnica, nenhuma habilidade profissional pode ser adquirida sem exercício; não se pode mais aprender a arte de viver, a technê tou blou, sem uma askêsis que deve ser compreendida como um treino de si por si mesmo: este era um dos princípios tradicionais aos quais, muito tempo depois, os pitagóricos, os socráticos, os cínicos deram tanta importância (FOUCAULT, 2014a, p. 143).

$\mathrm{Na}$ atualidade temos ouvido com frequência a frase "é preciso se cuidar", que nos remete a alguns preceitos da pós-modernidade como à busca por saúde física pelo cuidado com a alimentação e pela prática de exercícios físicos; ao cuidado com a aparência; ao cuidado com a mente; ou ainda, ao cuidado em desenvolver alguns valores como o otimismo, o amor próprio, a independência e a auto segurança; ao cuidado em desenvolver uma sólida carreira profissional. São enunciados que nos inundam com pressupostos de "como deve ser um sujeito pós-moderno" e que acabam prescrevendo modos de estar no mundo que conformam nossos corpos e nossas práticas.

A escola também está emaranhada nestes discursos que entendem como importante o cuidado de si na atualidade. Ou seja, diferentes profissionais atuam na escola, estabelecendo como devem ser as famílias, ou seja, o que pode ou não ser tolerado; o que deve ou não ser 
servido como merenda ou vendido nas cantinas escolares, a fim de que os alunos possam ter uma alimentação saudável; os incentivos a prática de exercícios físicos às crianças e até mesmo, de forma mais ampla, a obrigatoriedade do ensino também poderia ser compreendida como um cuidado do outro que aos poucos, conforme vamos nos tornando mais responsáveis por nós mesmos, se transforma em um cuidado de si. Assim, é possível perceber que o cuidado de si na atualidade, está bastante entrosado com o poder disciplinar e com a norma. É um "cuidado de si” prescrito por outros, ou seja, especialistas, para indivíduos no geral e que trata, menos de uma compreensão de si e mais de uma conformação de si, ou seja, de uma normação, a fim de que se possa ser o mais saudável ou normal possível. Neste sentido:

É na escola que aprendemos mais do que os conhecimentos específicos, que por si só já estão envoltos em relações de poder. Aprendemos a significar e valorar o mundo que nos cerca, por intermédio do currículo nele desenvolvido. Aprendemos o que é certo/errado, puro/impuro, normal/anormal, entre outros (DUARTE; MONTEIRO; ALMEIDA, 2018, p. 152).

Para pensarmos uma Docência em Matemática que possibilite maneiras outras de "seraluno" e de "ser-professor" e que de certo modo, possa romper um pouco com a disciplina e com a norma, nos aventuramos no conceito de cuidado de si da cultura greco-romana, que foi estudado por Foucault. Nossa intenção não é a de restabelecermos a sociedade antiga, ou ainda, defender ou interditar formas de pensar greco-romanas ou atuais, mas a de criar possíveis composições, pois "olhar para os gregos, mais do que um instrumento de conformação com o sujeito moderno, traz um modelo de constituição em que a ética é o elemento essencial. Daí a importância deste olhar" (FONSECA, 2016, p. 136). Neste sentido, uma estética da existência greco-romana pressuporia algumas artes de si, ou seja, exercícios que tinham como intenção tornar a vida bela, ou seja, a "vida como uma obra de arte" que pudesse ser contemplada tanto por si, quanto pelos outros; ou seja,

Um conjunto de práticas que certamente tiveram uma importância considerável em nossas sociedades: é o que se poderia chamar "artes da existência". Estas devem ser entendidas como as práticas racionais e voluntarias pelas quais os homens não apenas determinam para si mesmos regras de conduta, como também buscam transformar-se, modificar-se em seu ser singular, e fazer de sua vida uma obra que seja portadora de certos valores estéticos e que corresponda a certos critérios de estilo (FOUCAULT, 2014a, p. 193). 
Segundo Foucault (2014a), a cultura greco-romana do cuidado de si não se dirigia a todos, mas apenas àqueles que eram considerados cidadãos, ou seja, não era orientada nem aos escravos, nem às mulheres e nem aos estrangeiros, o que, de certa forma, se contrapõe ao momento histórico em que vivemos, pois na atualidade, é inadmissível discriminar pessoas por serem mulheres ou estrangeiros. Também era orientado que o cuidado de si começasse na juventude e que se estendesse até a velhice. Neste sentido, na ética greco-romana, segundo Fonseca (2016), há alguns elementos como: a determinação da substância, ou seja, qual parte de si será a matéria da conduta moral; como se reconhecerá ao cumprir esta moral, isto é, qual ideia fará de si mesmo ao seguir tais regras morais, e a elaboração do trabalho ético que seriam "atitudes de autoconhecimento, de controle, de aperfeiçoamento e de transformação de si, enfim, "práticas de si” que estão no fundamento da ação moral” (FONSECA, 2016, p. 101). A estética da existência pressupunha conhecer-se a si mesmo para que se pudesse alcançar a liberdade, ou seja, "não ser escravo de si mesmo, nem dos seus apetites, o que implica estabelecer consigo mesmo uma certa relação de domínio, de controle, chamada de arché - poder, comando (FOUCAULT, 2014a, p. 264) em relação ao seu corpo e à sua saúde, e no relacionamento com as mulheres e com os rapazes, a fim de tornar-se um cidadão livre, ou seja, de desenvolver um êthos belo. Conhecer a si mesmo também possibilitaria uma correspondência entre aquilo que se é e o que se pensa ser, ou seja, quando se percebe que não se é aquilo que se acredita ser, poder-se-á elaborar um trabalho ético, a fim de buscar a correspondência entre o pensar e o agir, ou seja, atuar sobre si, na busca pela perfeição dos seus atos. No entanto, o cuidado de si não era um processo espontâneo, mas uma objetivação de si por meio de um olhar de distanciamento do mundo, ou seja, era necessário não se deixar comandar por paixões e impulsos mundanos. Além disso, o cuidado de si não era um exercício solitário, mas era indicado que fosse realizado com a ajuda de alguém mais experiente e sábio, que pudesse ter aptidão para dirigir e para aconselhar, ou seja, “[...] é preciso chamar um outro, e é um outro que deve nos ajudar a cuidarmos bem de nós mesmos: donde a figura do mestre da existência" (GRÓS, 2006, p. 132). O cuidado de si pressupunha que se pudesse ter em seus atos uma certa correspondência com aquilo de que se fala. Assim, eram utilizadas técnicas como: conversações, a escrita de si, ensinamentos e aprendizagem em escolas, formações individuais, a fim de buscar uma estilização do agir. Neste sentido, eram

[...] tarefas práticas, atividades diversas. Ocupar-se de si não é uma sinecura. Existem os cuidados com o corpo, os regimes de saúde, os exercícios físicos sem excesso, a satisfação, tão medida quanto possível, das necessidades. 
Existem as meditações, as leituras, as anotações que se toma sobre livros ou conversações ouvidas, e que mais tarde serão relidas, a rememoração das verdades que já se sabe, mas de que convém apropriar-se ainda melhor" (FOUCAULT, 1985, p. 56-57).

A escrita de si poderia ser realizada de duas maneiras: em hupomnêmatas ou nas correspondências. Os hupomnêmatas eram cadernos onde se anotavam "citações, fragmentos de obras, exemplos e ações que foram testemunhadas ou cuja a narrativa havia sido lida, reflexões ou pensamentos ouvidos ou que vieram à mente" (FOUCAULT, 2014a, p. 144), a fim de que se pudesse realizar um "exercício do pensamento sobre ele mesmo [...]" (FOUCAULT, 2014a, p. 143) pela leitura e releitura do que se escrevia. A escrita de si se tratava de um exercício de si sobre si que pressuporia também a leitura, no entanto, esta não deveria ser em demasia, pois era compreendido que o seu exagero provocaria uma "agitação na mente" pelo fato de produzir o gosto pela novidade e mudanças frequentes de opinião, ou seja, uma instabilidade do pensamento e, ainda, uma mente voltada para o futuro, que por ser incerto, provocaria preocupações que inquietam a mente. No entanto, uma leitura feita de modo a sustentar o espírito era bem-vinda como alimento para a alma que após ser digerida, integraria o organismo e possibilitaria uma reflexão sobre o passado, a fim de buscar nos atos já realizados possíveis erros a serem corrigidos e acertos a serem perpetuados. Outra prática de escrita de si seriam as correspondências, que era o envio da escrita de si para outras pessoas. Neste sentido, "a carta que se envia age, por meio do próprio gesto da escrita, sobre aquele que a envia, assim como, pela leitura e releitura, ela age sobre aquele que a recebe" (FOUCAULT, 2014a, p. 150). A estética de si se tornaria uma escrita compartilhada com pessoas que se acreditava, hábeis para poder dar e receber conselhos que ajudariam no “cuidado de si". As cartas também agiriam como fonte de bons afetos, pois possibilitaria que uma pessoa sabia fosse analisada por outra pessoa sabia, ou seja, um exercício de objetivação da alma. Também viabilizaria o exame de consciência "para colocar a si mesmo sob os olhos do outro" (FOUCAULT, 2014a, p. 156), por meio de relatos de fatos diários, e aos quais se buscava saber se haviam agido de maneira adequada ou não e de como poder ir aperfeiçoando a sua existência, ou seja, qual dieta ou exercício físico seriam os mais adequados, como melhorar o sono, como exercitar a mente. Neste sentido, era necessário reservar um tempo, durante o dia, para o cuidado de si que permitisse

[...] ficar face a face consigo mesmo, recolher o próprio passado, colocar diante de si o conjunto da vida transcorrida, familiarizar-se, através da leitura, com os preceitos e os exemplos nos quais se quer inspirar e 
encontrar, graças a uma vida examinada, os princípios essenciais de uma conduta racional (FOUCAULT, 1985, p. 56).

Segundo Foucault (1985), o cuidado de si greco-romano era tratado como uma medicina do corpo e da alma. Isto é, não havia divisão entre a estrutura física e a psíquica e neste sentido, quando havia algum problema moral a ser melhorado, havia a compreensão de que o sujeito estava doente e deveria, deste modo, seguir um tratamento, a fim de restituir o equilíbrio.

Essas noções e esses esquemas devem servir como guia comum à medicina do corpo e à terapêutica da alma. Eles permitem não somente aplicar o mesmo tipo de análise teórica aos distúrbios físicos e às desordens morais como também seguir o mesmo gênero de abordagem para intervir em ambos, ocupar-se com eles, cuidá-los e, eventualmente, curá-los (FOUCAULT, 1985, p. 60).

É importante salientar que o indivíduo moderno, constituído pela norma, se difere do indivíduo antigo, constituído pela ética. Enquanto na ética é preciso se conhecer, ou seja, "cuidar de si consiste em conhecer-se a si mesmo. O conhecimento de si se torna o objeto da busca do cuidado de si” (FOUCAULT, 2014b, p. 273), a fim de se compor por meio de uma relação íntima consigo mesmo, para evitar qualquer tipo de dominação, seja pelo outro, ou por seus afetos e paixões; na norma, esta relação fica impedida de ocorrer, pois esta é sempre externa ao indivíduo e pressupõe, ainda, uma negação de si. Desta forma, não há o exercício de pensar o pensamento como há na ética greco-romana, mas uma submissão do pensamento, dos desejos e dos afetos à norma. Outra diferença seria a de que a norma é uma obrigação, ou seja, não se pode escolher segui-la e seria a mesma para todos, e exercida por um sujeito sobre o outro, em instituições ditas disciplinadoras, que excluiriam para incluir, ou seja, retirariam o indivíduo da sociedade por determinados períodos, a fim de que pudesse estar apto a integrála; já a ética greco-romana teria como característica ser de livre escolha, ou seja, tratar-se-ia da estilização que um indivíduo se propõe a realizar em sua existência e, por isso, é sempre singular e realizada no seu cotidiano, no seu viver diário.

Com isto, podemos compreender o cuidado de si como ferramenta que viabiliza diferentes olhares para a Docência e para a Matemática, pois possibilita outras formas de compreender o conhecimento que não somente o disciplinar. Neste sentido, talvez o cuidado de si greco-romano esteja sendo utilizado neste texto como "um outro fôlego" para pensar a Docência em Matemática. Um suspiro que nos enche de vontade de existência, mas não de uma existência pronta e acabada, mas de um aprender pela experimentação, pelos gostos, 
pelos sabores, pelos cheiros e pelas cores. Neste sentido, que a Docência em Matemática não seja apenas os ângulos retos, os quadrados e os diâmetros, mas que em nossas aulas possam também estar presentes a dúvida, os questionamentos, as problematizações e a curiosidade.

\section{Conclusão}

Meu papel - mas este é um termo muito pomposo - é mostrar às pessoas que elas são muito mais livres do que pensam, que elas tomam por verdadeiros, por evidentes certos temas fabricados em um momento particular da história, e que essa pretensa evidência pode ser criticada e destruída (FOUCAULT, 2014a, p. 288).

Arriscar uma Docência em Matemática que nos mobilize a pensar diferente, ou ainda, a pensar o que nos é impensado neste momento, para talvez criar fissuras na Docência e fazer emergirem docências outras que não tenham uma identidade, mas singularidades diversas, a fim de que, no currículo escolar, possam "estar presentes diferentes formas de matematizar o mundo, todavia com o cuidado de que tal incorporação possa empoderar o outro e não subordiná-lo a matemática hegemônica" (DUARTE; MONTEIRO; ALMEIDA, 2018, p. 149). Desta forma, acreditamos na necessidade de (in)disciplinar a Docência em Matemática, para tensionar as suas linhas, e assim, fazer soar outros sons, ou ainda "achar seu próprio ponto de subdesenvolvimento, seu próprio dialeto, seu próprio terceiro mundo, seu próprio deserto" (DELEUZE, 2014, p. 39). Nossa intenção é a de que possam emergir docências da experimentação, docências da vida, docências de rua, docências mestiças, para que possamos, talvez, "resistir à reprodução da representação das docências-dadas pelo ato de pensar, de escrever e de repetir, considerando uma docência em meio à vida, para potencializar a invenção de uma docência, é um movimento de subversão que se dá pela experimentação" (AURICH, 2017, p. 76). Neste sentido, acreditamos que esta escrita pretendeu ser instrumento para pensar em docências que possibilitem a todos "um cuidado de si" que viabilize "um cuidado com o outro". Ou seja, o cuidado de si greco-romana pode ser uma ferramenta potente, pois possibilita olhar com outras lentes a nossa existência e o mundo pela invenção de si, que pode ser impulsionadora para a criação de outras docências e do próprio docente pela ação de ensinar. Compreendemos ainda que se "a vida apenas tem encontros; todo o resto são descoincidências (COUTO, 2010, p. 199) é na sala de aula, ouvindo os alunos e as nossas sensações, que acontecem esses encontros. Encontros que se dão na escuta do outro e na escuta de si; ou/e na escuta de si que é também a escuta do outro ou/e na escuta do outro que é também a escuta de si. Assim, são nos ecos e nas coisas que ecoam em nós que podemos ir 
tateando maneiras de ser outro, ou seja, no cuidado grego, não havia separação entre o corpo e a alma. Com isto, a Docência poderia experimentar aprender com o corpo e com aquilo que faz sentir; com o ambiente e com as sensações. Desta forma, como o sujeito grego que olha para si e para o mundo, que procura se reinventar, a fim de se transformar em sua própria obra de arte, possamos também, tatear outras docências, experimentar outros modos de ser, para criar uma docência amorosa e intuitiva, que possibilite irrigar com vida os saberes aprendidos na escola, para que possamos, ainda, nos surpreender com o mundo e com nós mesmos. Propomos docências em matemática nômades e estrangeiras, que falem outras línguas ou línguas outras. No entanto, não acreditamos que "vale tudo" na escola, pois entendemos como importante um certo "cuidado científico", mas que este não nos deixe míopes para a vida e para o mundo. Talvez possamos pensar em docências que possibilitem (re) olhares, a fim de que possamos não acreditar como intransponíveis os conhecimentos que nós mesmos [os outros] construímos na caótica e indomável existência.

\section{Referências}

AURICH, Grace da Ré. Reescrita de si: a invenção de uma docência em matemática. 2017. 152f. Tese (Doutorado em Educação) - Programa de Pós-Graduação em Educação, Faculdade de Educação, Universidade Federal do Rio Grande do Sul, Porto Alegre, 2017.

BRAIDA, Celso Reni. A crítica do conhecimento em Nietzsche. In: TÜRCKE, Chistoph (Org.). Nietzsche: Uma provocação. Porto Alegre: Ed. UFRGS, 1994, p. 33-42.

CARVALHO, Alexandre Filordi. Sociedade capitalista e produção disciplinar excludente: a atualidade de Vigiar e Punir na compreensão da função-sujeito contemporânea. In: CARVALHO, Alexandre Filordi; GALLO, Silvio. Repensar a Educação 40 anos após Vigiar e Punir. São Paulo: Livraria da Física, 2015. 461p. p. 175- 207.

COUTO, Mia. Olhos nus: olhos. In: BRESSANE, Ronaldo. Essa história está diferente: dez contos para canções de Chico Buarque. São Paulo: Companhia das Letras, 2010. 259p. p. 197-215.

DELEUZE, Gilles. Kafka: por uma literatura menor. Belo Horizonte: Autêntica, 2014. 157p.

DUARTE, Claudia Glavam; MONTEIRO, Carlos Eduardo Ferreira; ALMEIDA, Ana Quele Gomes de. Por uma política do ínfimo: relações étnico-raciais em suas interfaces com a Educação Matemática. Revista de Educação, Ciência e Cultura, Canoas, v. 23, n. 1, p. 149160, 2018.

FONSECA, Márcio Alves da. Michel Foucault e a Constituição do Sujeito. São Paulo: EDUC, 2016. 144p. 
FOUCAULT, Michel. A Cultura de si. In: FOUCAULT, Michel. História da Sexualidade III: o cuidado de si. Rio de Janeiro: Edições Graal, 1985. p. 43-73.

FOUCAULT, Michel. Vigiar e punir: nascimento da prisão. Petrópolis, RJ: Vozes, 1999.

FOUCAULT, Michel. Segurança, território e população: curso dado no Collège de France (1977-1978). São Paulo: Martins Fontes, 2008.

FOUCAULT, Michel. Ética, sexualidade, política. Rio de Janeiro: Forense Universitária, 2014a. 325p.

FOUCAULT, Michel. Genealogia da ética, subjetividade e sexualidade. Rio de Janeiro: Forense Universitária, 2014b. 312p.

GROS, Frédéric. O cuidado de si em Michel Foucault. In: RAGO, Margareth; VEIGANETO, Alfredo. Figuras de Foucault. Belo Horizonte: Autêntica, 2006. 296p. p. 127-138.

PARAÍSO, Marlucy Alves. Metodologias de pesquisas pós-críticas em educação e currículo: trajetórias, pressupostos, procedimentos e estratégias analíticas. In: MEYER, Dagmar Estermann; PARAÍSO, Marlucy Alves (Org.). Metodologias de Pesquisas Pós-críticas em Educação. Belo Horizonte: Mazza Edições, 2014. 310p. p. 25-47.

PINHEIRO, Josaine de Moura. Estudantes Forjados nas Arcadas do Colégio Militar de Porto Alegre (CMPA): "Novos Talentos" da Olimpíada Brasileira de Matemática das Escolas Públicas (OBMEP). 2014. 228 f. Tese (Doutorado em Educação) - Programa de PósGraduação em Educação, Universidade do Vale do Rio dos Sinos, São Leopoldo, 2014.

VEIGA-NETO, Alfredo. A ordem das disciplinas. 1996. 339f. Tese (Doutorado em Educação) - Universidade Federal do Rio Grande do Sul, Porto Alegre, RS, 1996.

VEIGA-NETO, Alfredo; LOPES, Maura Corcini. Inclusão e governamentalidade. Educação e Sociedade, Porto Alegre, v. 28, p. 947-963, 2007.

VEIGA-NETO, Alfredo. Uma vila voltada para trás. In: GALLO, Silvio; VEIGA-NETTO, Alfredo. Fundamentalismo e Educação. Belo Horizonte: Autêntica, 2009. 240p. p. 67-106.

WALKERDINE, Valerie. O raciocínio em tempos pós-modernos. Educação e Realidade, Porto Alegre, v. 20, n. 2, p. 207-226, 1995. 